\title{
REGULATION OF CALCIUM ENTRY INTO THE EXTRACELLULAR ENVIRONMENT OF THE RAT BRAIN ${ }^{1}$
}

\author{
AMIRAM I. BARKAI ${ }^{2}$ AND HERBERT L. MELTZER
}

New York State Psychiatric Institute and Departments of Psychiatry and Biochemistry, Columbia University, College of Physicians and Surgeons, New York, New York 10032

Received January 26, 1982; Revised March 30, 1982; Accepted April 7, 1982

\begin{abstract}
Since neuronal activity is critically related to both intra- and extracellular calcium ion concentrations, there must be a mechanism for regulating the transfer of calcium from the blood into the extracellular environment of the brain. The data presented here support the hypothesis that, within or close to the site of passive permeation of calcium in the choroid plexus, there is a calcium pump capable of recycling the filtered calcium back into the capillary circulation. This pump can be blocked by ruthenium red, a known inhibitor of active calcium transport. The activity of the calcium pump is shown to increase in proportion to the concentration of calcium in the cerebroventricular fluid. Its physiological role therefore would be to insure that the calcium concentration available to the brain will be maintained within a narrow range even in the presence of severe hypercalcemic states.
\end{abstract}

The concentration of calcium $(\mathrm{Ca})$ in the cerebrospinal fluid (CSF) of various mammals is known to be maintained within a relatively limited range even in the presence of marked changes in Ca levels in plasma and body fluids (reviewed in Katzman et al., 1968; Graziani et al., 1967). The entry of calcium from the plasma into the cerebroventricular compartment appears to be largely independent of the plasma concentration. It has been suggested, therefore, that the entry of calcium into the CSF may be controlled by a carrier-mediated or active transport mechanism (Graziani et al., 1967). However, more recent studies of ion transport across the choroid plexus produced no evidence that calcium is actively transported across this tissue (Wright, 1972). While an operative carrier-mediated transport may play an important role during hypocalcemia, it is not likely to be the only process controlling the entry of $\mathrm{Ca}$ into the CSF, particularly during states of hypercalcemia when diffusion favors an enhanced net flow of $\mathrm{Ca}$ from the blood to the CSF.

Newly formed CSF has been shown to be a major source of $\mathrm{Ca}$ ions entering the cerebroventricular com-

\footnotetext{
${ }^{1}$ This work was supported in part by Grant 1715 from the New York State Health Research Council and Grants MH32569 and MH33690 from the National Institutes of Health. We wish to thank Mr. Spencer Erman for his excellent technical assistance and Ms. Ann Kelly for typing the manuscript.

${ }^{2}$ To whom correspondence should be addressed at New York State Psychiatric Institute, 722 West 168th Street, New York, NY 10032.
}

partment at rates independent of the plasma concentration (Cserr, 1971). It might be expected, therefore, that $\mathrm{Ca}$ extrusion occurs at sites of CSF formation, such as the choroid plexus. An operative extrusion process may have an important role in controlling the net entry of $\mathrm{Ca}$ from the blood to the CSF, particularly at times when the plasma concentration of Ca exceeds that of the CSF. It is possible that such a Ca extrusion mechanism responds to elevated $\mathrm{Ca}$ concentrations in the CSF surrounding the choroid plexus by reducing the net flow of $\mathrm{Ca}$ from the blood to the cerebroventricular compartment.

The purposes of the present study were to determine whether the rate of appearance of $\mathrm{Ca}$ in the cerebroventricular compartment is dependent upon the concentration of $\mathrm{Ca}$ in the cerebroventricular fluid which surrounds the choroid plexus and to investigate some of the possible mechanisms which control the entry and removal of calcium in the cerebroventricular compartment of the urethane-anesthetized rat.

\section{Materials and Methods}

Animals. Male Wistar rats weighing 200 to $250 \mathrm{gm}$ were used. The animals were deprived of food for $18 \mathrm{hr}$, but water was allowed ad libitum.

Operative procedure. The rat was anesthetized with urethane $(1 \mathrm{gm} / \mathrm{kg}$, i.p.) and placed in a stereotaxic frame. The skull and dorsal neck muscles were exposed. The neck muscles were separated at the occipital protuberance to gain access to the atlanto-occipital membrane. A 
small burr hole was drilled $0.5 \mathrm{~mm}$ anterior to bregma and $1 \mathrm{~mm}$ laterally from the midline for the insertion of the inflow cannula into the lateral ventricle.

Ventricular-cisternal perfusion. A push-pull system consisting of two infusion-withdrawal pump-driven syringes was used as previously described (Barkai, 1981). Briefly, artificial CSF (Cserr, 1965) was perfused via an inflow cannula ( 27 gauge needle) located in the lateral ventricle and the effluent was collected from an outflow cannula in the cisterna magna. Perfusion was carricd out at a constant rate of $6.8 \mu \mathrm{l} / \mathrm{min}$. Effluent was collected in a segment of calibrated polyethylene tubing which was replaced at predetermined time intervals. The perfusion fluid contained a tracer amount of ${ }^{45} \mathrm{CaCl}_{2}$. The specific radioactivity $(S A)$ of the ${ }^{45} \mathrm{Ca}$ varied according to the experimental design. The concentration of $\mathrm{Ca}$ in the artificial CSF varied in different experiments between 0.08 and $12 \mathrm{~mm}$. The osmolality was kept constant by reducing the sodium concentration when high $\mathrm{Ca}$ concentrations were used.

Assay of Ca specific activity. The calcium concentration was determined in 50- $\mu \mathrm{l}$ aliquots of either perfusion fluid or effluent. The sample was diluted with deionized water to a final concentration of 20 to $50 \mu \mathrm{M}$ and the $\mathrm{Ca}$ content was determined by atomic absorption (PerkinElmer model 372). An air/acetylene flame was used and the integration time of each sample was set to $2 \mathrm{sec}$. The full scale standard was a $50 \mu \mathrm{M}$ solution of $\mathrm{CaCl}_{2}$. Radioactivity was assayed in duplicate $10-\mu \mathrm{l}$ aliquots using a scintillation spectrometer (Beckman Instruments LS200 ) and the specific activily was expressed as counts per min per nmol of calcium.

Determination of the rate of appearance of calcium. The rate of appearance of endogenous calcium $\left(R_{a}\right)$ in the perfused cerebroventricular compartment was estimated by isotope dilution kinetics according to the equation:

$$
R_{a}=V_{\text {in }} C_{\text {in }}\left[\left(S A_{\text {in }} / S A_{\text {out }}\right)-1\right]
$$

where $R_{a}$ is the average rate of appearance of endogenous calcium in the steady state, $C_{\text {in }}$ is the concentration of calcium in the perfusion fluid, and $V_{\text {in }}$ is the volume perfused per time unit when $S A_{\text {in }}$ and $S A_{\text {out }}$ are specific activity values for ${ }^{45} \mathrm{Ca}$ in the perfusion fluid and effluent, respectively, after isotopic steady state has been reached.

Entry of $\mathrm{Ca}$ from the blood. Estimates of Ca clearance from the plasma into the cerebroventricular compartment were made after rapid intravenous injection of the tracer ${ }^{45} \mathrm{Ca}$ and continuous sampling of cisternal effluent. During the early period (first $5 \mathrm{~min}$ ) after the tracer injection, when the amount of tracer that is returned to the plasma is practically negligible, the concentration of the tracer in the cerebroventricular compartment at any particular time after tracer injection can be calculated from the equation:

$$
\left[{ }^{*} C\right]_{v(t)}=\frac{K_{p l \rightarrow v}}{K_{p l}}\left[{ }^{*} C\right]_{p l(t=0)}\left(1-e^{-K} p l^{t}\right)
$$

where ${ }^{*} C_{v(t)}$ is the concentration of tracer in the cerebroventricular compartment at time $t$ after tracer injection, $K_{p l \rightarrow u}$ is the rate constant for the clearance of the tracer from the plasma into the cerebroventricular fluid, $K_{p l}$ is the rate constant of the total clearance of the tracer from the plasma, and ${ }^{*} C_{p l(t=0)}$ is the concentration of tracer in the plasma immediately following tracer injection. It appears from this relationship that, when ${ }^{*} C_{v(\ell)}$ represents ${ }^{45} \mathrm{Ca}$, the values of ${ }^{*} C_{v(t)} /{ }^{*} C_{p l(t=0)}$ approach the asymptote $K_{p l \rightarrow v} / K_{p l}$ with a half-life that is determined by $K_{p l}$ (i.e., the rate of the total clearance of ${ }^{45} \mathrm{Ca}$ from the injected plasma compartment (Riggs, 1963)). In order to estimate $K_{p l}$ and $K_{p l \rightarrow v}$, animals were injected with 0.2 $\mathrm{ml}$ of saline solution containing a tracer amount of ${ }^{45} \mathrm{Ca}$ (30 to $50 \mu \mathrm{Ci}$ ) and cercbroventricular effluent was collected at short time intervals $(\sim 20$ to $40 \mathrm{sec})$ in the withdrawal polyethylene tubing. Thus, ${ }^{*} C_{n(t)}$ values were obtained experimentally during a 6 -min period. ${ }^{*} C_{p l(t=0)}$ was obtained after the total amount of tracer injected was divided by $5 \%$ of the animal's body weight (representing plasma volume) and $K_{p l}$ and $K_{p l \rightarrow v}$ were calculated from the experimental data by nonlinear regression analysis (BMDP 3R, UCLA, 1979) according to equation 2 above.

Calcium removal. The fraction $F$ of calcium removed from the CSF compartment by all internal mechanisms (endogenous removal) is obtained under steady state conditions from the following equation:

$$
F=1-\left({ }^{*} C_{\text {out }} /{ }^{*} C_{\text {in }}\right)
$$

where ${ }^{*} C_{\text {out }}$ and ${ }^{*} C_{\text {in }}$ are the concentrations (counts per min per $\mathrm{ml}$ ) of ${ }^{45} \mathrm{Ca}$ in the effluent and the perfusion fluid, respectively. Internal mechanisms for the removal include diffusion and bulk absorption of the CSF through the arachnoid villi. The product of $F\left(C_{\text {in }} V_{\text {in }}+R_{a}\right)$ represents the rate of endogenous removal (nanomoles per min) by the internal transport mechanisms.

Assay of ${ }^{45} \mathrm{Ca}$ in the brain and choroid plexus. At the end of the perfusion experiment, the rat was removed form the stercotaxic frame and immediately decapitated. The brain was removed and weighed. The choroid plexuses of the lateral ventricles were dissected out, washed briefly in saline, blotted, and immersed in $0.5 \mathrm{ml}$ of $1 \mathrm{~N}$ $\mathrm{NaOH}$ solution in a small stoppered vial. The brain was washed twice in saline solution and placed in a vial to which tissue solubilizer (Protosol, New England Nuclear) was added to bring the volume up to $10 \mathrm{ml}$. This vial then was stoppered and left in an oven at $55^{\circ} \mathrm{C}$ for 1 week, with occasional shaking, until the tissue was solubilized completely. The volume was adjusted again to 10 $\mathrm{ml}$ with the same tissue solubilizer and the vial was left at room temperature in the dark for an additional $24 \mathrm{hr}$. Triplicate aliquots of $0.5 \mathrm{ml}$ each then were taken for the measurement of radioactivity. Samples were counted in a Beckman scintillation spectrometer. Counting efficiency was corrected to match that of the aqueous samples and radioactivity was expressed as counts per min per gm.

The vial containing the choroid plexus tissue was left at room temperature until the tissue was dissolved completely, usually 3 days. Duplicate aliquots of $0.1 \mathrm{ml}$ were taken for protein determination according to Lowry et al. (1951). The remaining $0.3 \mathrm{ml}$ was transferred to a scintillation vial and titrated with $0.3 \mathrm{ml}$ of $1 \mathrm{~N} \mathrm{HCl}$. The mixture then was "bleached" with $0.1 \mathrm{ml}$ of $3 \% \mathrm{H}_{2} \mathrm{O}_{2}$ solution and radioactivity was assayed after the addition of $18 \mathrm{ml}$ of scintillation fluid. Radioactivity was deter- 
mined as counts per min per mg of protein. Since the mean value for protein content in choroid plexus tissue was found in separate experiments to be $98 \mu \mathrm{g} / \mathrm{gm}$ (SD $=18$ ), the radioactivity data were multiplied by 100 to represent counts per min per gm of tissue.

\section{Results}

Rate of appearance of endogenous $C a\left(R_{a}\right)$. In a typical experiment, when the cerebroventricular compartment was perfused at a constant rate $\left(V_{\text {in }}=6.8 \mu \mathrm{l} /\right.$ min) with artificial CSF-containing ${ }^{45} \mathrm{Ca}\left(C_{\text {in }}=1.3 \mathrm{~mm}\right.$; $S A_{\text {in }}=1123 \mathrm{cpm} / \mathrm{nmol}$ ), an apparent isotopic steady state was reached within $40 \mathrm{~min}$ and the $S A$ of $\mathrm{Ca}$ in the effluent $\left(S A_{\text {out }}\right)$ had a mean value of $750 \mathrm{cpm} / \mathrm{nmol}$ which remained practically constant until the experiment was terminated 80 min later (Fig. 1). When this $S A_{\text {out }}$ value was substituted in equation 1 above, a mean $R_{a}$ value of $4.5 \mathrm{nmol} / \mathrm{min}$ was obtained for this individual animal. Analysis of the data from 16 animals which were perfused with increasing $\mathrm{Ca}$ concentrations resulted in a negative relationship between the entry of $\mathrm{Ca}$ into the cerebroventricular compartment $\left(R_{a}\right)$ and the concentration of $\mathrm{Ca}$ in the cerebroventricular fluid (Fig. 2). Thus, at the lower concentration of $0.3 \mathrm{~mm} \mathrm{Ca}$ in the cerebroventricular fluid, the value for $R_{a}$ was $6.2 \mathrm{nmol} / \mathrm{min}$ (SD = 1.2 ), whereas at the extremely high concentration of 8.5 $\mathrm{mM} \mathrm{Ca}$, the value for $R_{a}$ was much lower and averaged at $0.5 \mathrm{nmol} / \mathrm{min}(\mathrm{SD}=0.16)$.

When the perfusion fluid contained the mucopolysaccharide stain ruthenium red-an inhibitor of the $\mathrm{Ca}$ pump (Watson et al., 1971) -at a final concentration of $0.1 \mathrm{mM}$, there appeared to be a significant increase in $R_{a}$ values and the negative relationship between $R_{a}$ and $C_{v}$ was no longer apparent (Fig. 2).

Entry of Ca from the blood. The experiments designed to estimate the value of $K_{p l \rightarrow v}$ were carried out with artificial CSF containing $1.3 \mathrm{~mm} \mathrm{Ca}$. The results show that the values of ${ }^{*} C_{v(t)}$ approach an asymptote with a

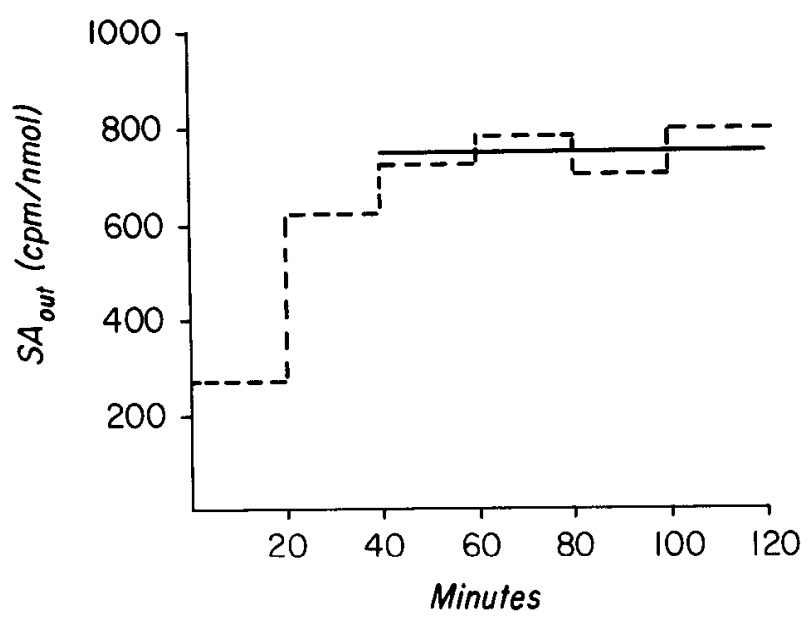

Figure 1. Change of ${ }^{45} \mathrm{Ca}$ specific activity in the effluent $\left(S A_{\text {out }}\right)$ with time during a typical ventriculocisternal perfusion. The calcium concentration in the perfusion fluid $\left(C_{\text {in }}\right)$ was 1.3 $\mathrm{mM}$ and $S A_{\text {in }}$ was $1123 \mathrm{cpm} / \mathrm{nmol}$. The solid horizontal line indicates the mean $S A_{\text {out }}$ value during isotopic steady state, which was used for the calculation of $R_{a}$ according to equation 1.

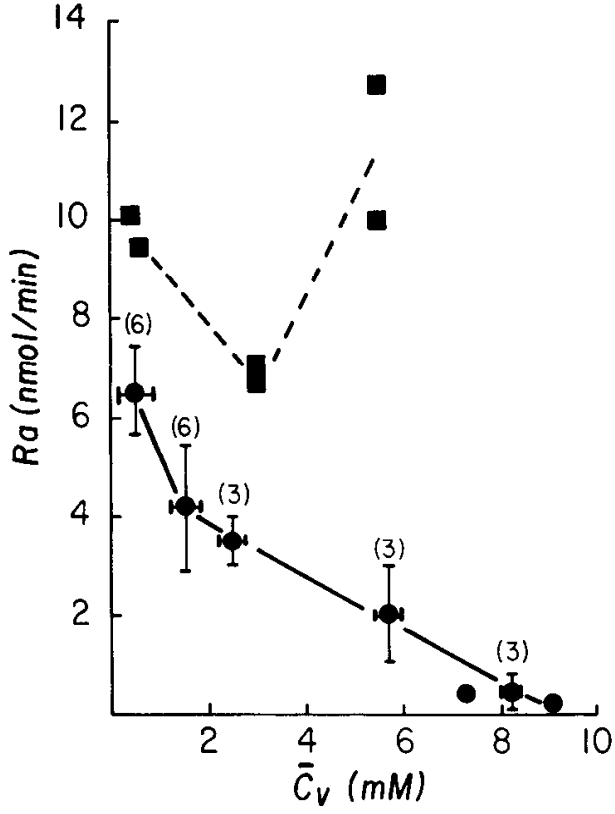

Figure 2. Relationship between the rate of appearance $\left(R_{a}\right)$ and the concentration of calcium in the cerebroventricular compartment. The values of $\bar{C}_{v}$ were calculated as exponential means of the concentrations in the perfusion fluid $\left(C_{\text {in }}\right)$ and the effluent $\left(C_{\text {out }}\right)$. The solid line represents the results from un treated rats; the horizontal bars denote the range of $\bar{C}_{v}$; the vertical bars indicate $1 \mathrm{SD}$ of the mean $R_{a}$ value. The numbers in parentheses indicate the number of animals used to establish each point. The upper curve (dashed line) represents the results from experiments in which ruthenium red $(0.1 \mathrm{~mm})$ was present in the perfusion fluid.

half-life of $1.83 \mathrm{~min}$, which corresponds to a value of $0.3230 / \mathrm{min}$ for $K_{p l}$ at the early period (0 to $5 \mathrm{~min}$ ) after the ${ }^{45} \mathrm{Ca}$ injection (Fig. 3). The rate constants $K_{p l}$ and $K_{p l \rightarrow v}$ were found by nonlinear regression analysis from the experimental data as described under "Materials and Methods." The mean value for $K_{p l \rightarrow v}$ was $7.53 \times 10^{-3} \mathrm{ml} /$ $\mathrm{min} / \mathrm{ml}$ of ventricular fluid, indicating that $7.53 \mu \mathrm{l}$ of plasma are cleared each minute from $1 \mathrm{ml}$ of plasma into $1 \mathrm{ml}$ of perfusate. Since the volume of the perfused cerebroventricular compartment in the adult rat is approximately $0.2 \mathrm{ml}$ (Simpson and Barkai, 1980), the mean value for ${ }^{45} \mathrm{Ca}$ clearance from plasma into CSF is $1.5 \mu \mathrm{l} /$ min. At the average plasma concentration of $2.1 \mathrm{~mm}$ (SD $=0.3$ ) determined for these rats, the clearance of $1.5 \mu \mathrm{l} /$ min is equivalent to the entry of $3.16 \mathrm{nmol} / \mathrm{min}$ of endogenous $\mathrm{Ca}$ from the blood plasma into the cerebroventricular compartment. This value represents approximately $75 \%$ of the $R_{a}$ value of $4.2 \mathrm{nmol} / \mathrm{min}$ obtained under similar conditions with the method of continuous tracer perfusion (Fig. 2). Thus, it appears that the majority of the endogenous $\mathrm{Ca}$ entering the cerebroventricular compartment of the rat originated in the blood.

Removal of $\mathrm{Ca}$ from the cerebroventricular compartment. The removal of ${ }^{45} \mathrm{Ca}$ was studied at different concentrations of $\mathrm{Ca}$ in the perfusion fluid $\left(C_{\text {in }}\right)$, ranging from 0.08 to $12 \mathrm{~mm}$. The fraction $F$ of the total $\mathrm{Ca}$ (endogenous and exogenous) entering the cerebroventricular compartment, which is removed by endogenous mechanisms, did not change significantly with increasing 


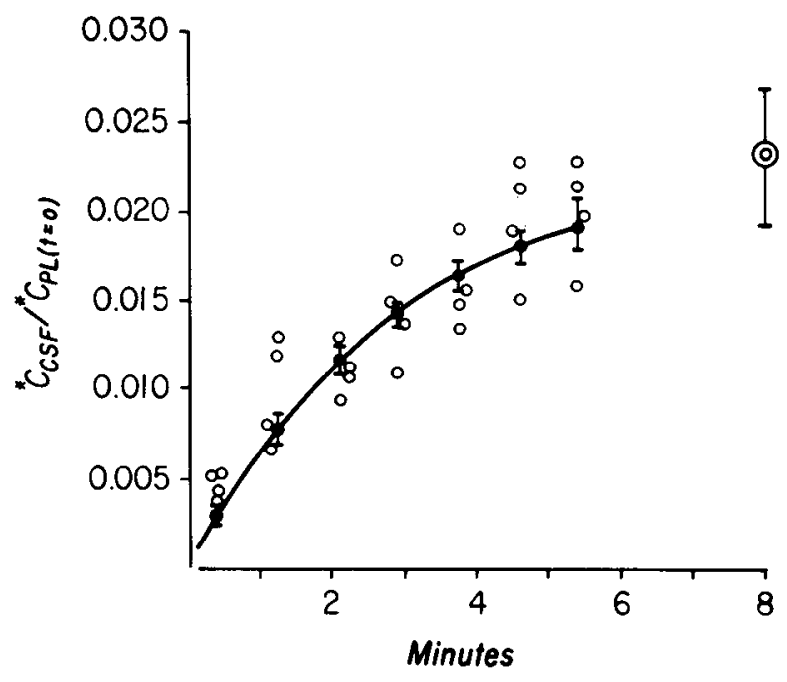

Figure 3. Change of ${ }^{45} \mathrm{Ca}$ radioactivity in the cerebroventricular compartment $\left({ }^{*} C_{c s f}\right)$ with time after a single intravenous injection of ${ }^{45} \mathrm{CaCl}_{2}$ at $t=0$. The data points are depicted as a fraction of the radioactivity present in $1 \mathrm{ml}$ of plasma at the time of injection, ${ }^{*} C_{p l(t=0)}$. $O$, Data from four separate experiments; - calculated means obtained by nonlinear regression analysis using the BMDP $3 \mathrm{R}$ program to solve for equation 2. The bars represent the standard deviation. The calculated asymptote is represented by the large circle at the extreme right. The approach to the asymptote is determined by $K_{p l}$ which is the rate constant for the clearance of ${ }^{45} \mathrm{Ca}$ from the plasma. The "best fit" according to equation 2 was:

$$
{ }^{*} C_{v(t)}={ }^{*} C_{p l(t=0)} \times 0.02332\left(1-e^{-0.3230 t}\right)
$$

Ca concentrations and had a mean value of $F=0.48$ (SD $=0.05$ ). Thus, the removal of Ca from the perfusate appears to be concentration dependent as might be expected by simple diffusion and bulk absorption. Ruthenium red had no apparent effect on the fractional removal either at low or at high Ca concentrations (Fig. 4).

Relationship between Ca concentrations in the perfusion fluid and effluent. At the steady state, the following relationship exists:

$$
C_{\text {in }} V_{\text {in }}+R_{a}-\left(C_{\text {in }} V_{\text {in }}+R_{a}\right) F=V_{\text {out }} C_{\text {out }}
$$

where $C_{\text {in }}$ and $C_{\text {out }}$ are millimolar concentrations of $\mathrm{Ca}$ in the perfusion fluid and effluent, respectively, $V_{\text {in }}$ and $V_{\text {out }}$ are the rates (microliters per min) of infusion and withdrawal, respectively, $R_{a}$ is the endogenous rate of appearance of $\mathrm{Ca}$ in the CSF compartment (nanomoles per $\min$ ), and $F$ is the fractional removal by endogenous mechanisms. Under the present experimental conditions, when $V_{\text {in }}=V_{\text {out }}$, the above equation can be modified to express $C_{\text {out }}$ as a function of $C_{\text {in }}$ :

$$
C_{\text {out }}=C_{\text {in }}(1-F)+R_{a}(1-F) / V_{\text {in }}
$$

It appears, therefore, that the relationship between $C_{\text {out }}$ and $C_{\text {in }}$ is linear with a slope of $1-F$ and an intercept of $R_{a}(1-F) / V_{\text {in }}$ at an $R_{a}$ value corresponding to $C_{\text {in }}=0$. A linear regression analysis of the experimental values for $C_{\text {out }}$ versus $C_{\text {in }}$ from untreated rats resulted in a slope, 1 $-F$, of 0.5 , and the intercept at $C_{\text {in }}=0$ was also 0.5 (Fig. $5)$. The calculated slope corresponds to a value of $F=$ 0.5 , which is very close to the mean value of $F$ obtained with the isotope technique (Fig. 4). The intercept of the regression line at $C_{\text {in }}=0$ corresponds to a value of $R_{a}=$ $6.8 \mathrm{nmol} / \mathrm{min}$, which is also in good agreement with the $\boldsymbol{K}_{a}$ value of $6.2 \mathrm{nmol} / \mathrm{min}$ obtained with the isotope dilution method at the lowest applied $\mathrm{Ca}$ concentration of $C_{\text {in }}=0.08 \mathrm{~mm}$ (corresponds to $C_{v}=0.3 \mathrm{~mm}$ in Fig. 2). Similar analysis of the data from experiments in which ruthenium red was present in the perfusion fluid resulted in a slope, $1-F$, of 0.49 . This slope corresponds to $F=$ 0.51 which is not significantly different from the value of $F$ obtained for untreated animals. However, in the ruthenium red experiments, a higher value of $0.86 \mathrm{~mm}$ was obtained for the $C_{\text {out }}$ intercept. This intercept corresponds to an $R_{a}$ value of $11.8 \mathrm{nmol} / \mathrm{min}$ which is $73 \%$

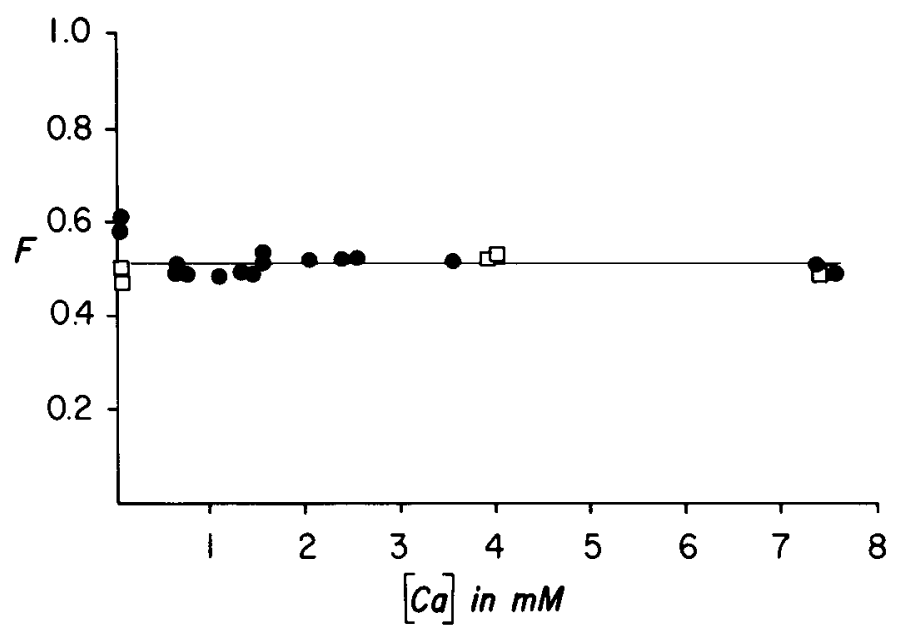

Figure 4. Relationship between the fraction $F$ of ${ }^{45} \mathrm{Ca}$ removed from the perfusate by endogenous mechanisms and the concentration of unlabeled calcium in the perfusion fluid. $F$ values remained practically unchanged with increasing $\mathrm{Ca}$ concentrations. The line represents the mean value of $F=0.48$ in untreated animals (O). The mean $F$ value in ruthenium red experiments $(\square)$ was not significantly different.

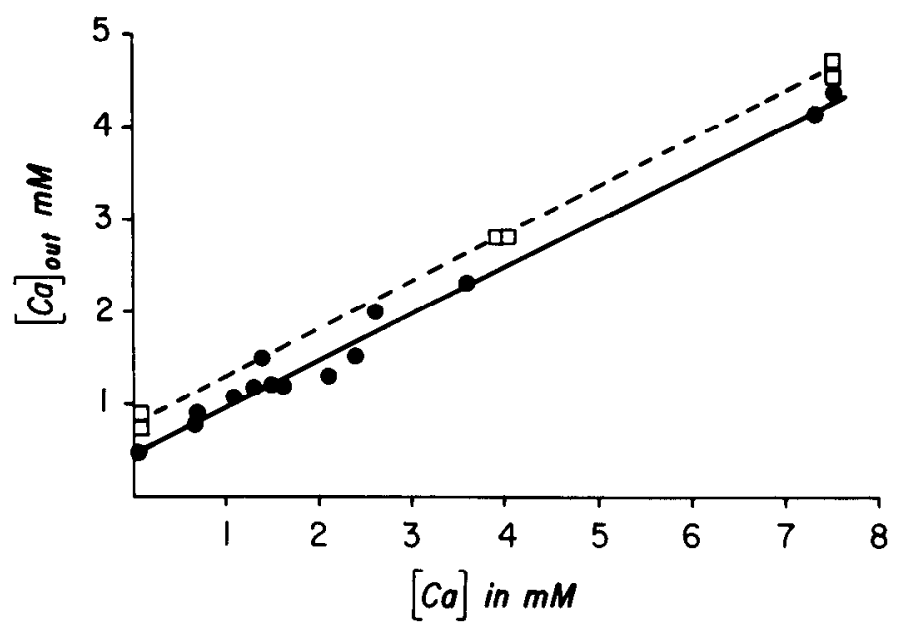

Figure 5. Relationship between calcium concentrations in the perfusion fluid $\left(C_{\text {in }}\right)$ and effluent $\left(C_{\text {out }}\right)$ in untreated rats (O) and in rats perfused with $0.1 \mathrm{~mm}$ ruthenium red ( $\square$ ). Intercepts and slopes were determined by linear regression using the method of least squares. In untreated rats, $C_{\text {out }}=0.50$ $+0.5 C_{\text {in }}$, whereas in ruthenium red experiments, $C_{\text {out }}=0.86$ $+0.49 C_{\mathrm{in}}$. The slopes and intercepts are related to $F$ and $R_{\mathrm{a}}$ as shown in equations 4 and 5 in the text. 
higher than the $R_{a}$ of $6.8 \mathrm{nmol} / \mathrm{min}$ obtained for the untreated animals. This $R_{a}$ value of $11.8 \mathrm{nmol} / \mathrm{min}$ is in good agreement with the $R_{a}$ value of $10 \mathrm{nmol} / \mathrm{min}$ obtained with the isotope dilution method in the presence of ruthenium red at the calcium concentration $C_{\text {in }}=0.08$ mM.

Uptake of ${ }^{45} \mathrm{Ca}$ by brain and choroid plexus tissues. When the concentration of ${ }^{45} \mathrm{Ca}$ in the tissue (counts per min per gm) at the end of the perfusion period is divided by the mean steady state concentration of ${ }^{45} \mathrm{Ca}$ in the ventricular fluid $\left({ }^{*} C_{v}\right)$, the resulting value represents the volume of the distribution of ${ }^{45} \mathrm{Ca}$ in the tissue (milliliter per gm) expressed in terms of the extracellular fluid (the volume of fluid required to maintain the amount of ${ }^{45} \mathrm{Ca}$ in the tissue at the same concentration as ${ }^{*} C_{v}$ ).

In the brain, the volume of distribution for ${ }^{45} \mathrm{Ca}$ at a $C_{v}$ of $0.3 \mathrm{~mm}$ was $0.12 \mathrm{ml} / \mathrm{gm}$. The volume of distribution in brain tissue was independent of the $\mathrm{Ca}$ concentration in the ventricular fluid $\left(C_{v}\right)$ over a wide range of $C_{v}$, values (Fig. 6). In choroid plexus, however, higher values for the ${ }^{45} \mathrm{Ca}$ volume of distribution were found for the lower $C_{v}$ of $0.3 \mathrm{~mm}$ than for higher $C_{v}$ values. Thus, at $C_{v}=0.3$ $\mathrm{mM}$, the mean volume of distribution was $0.48 \mathrm{ml} / \mathrm{gm}$, whereas at the range of $C_{v}$ between 1.3 and $7.5 \mathrm{~mm}$, the volume of distribution had a lower value of $0.2 \mathrm{ml} / \mathrm{gm}$ (Fig. 6).

Since the fractional removal of ${ }^{45} \mathrm{Ca}$ from the ventricular fluid to the brain was found to be independent of $C_{v}$,

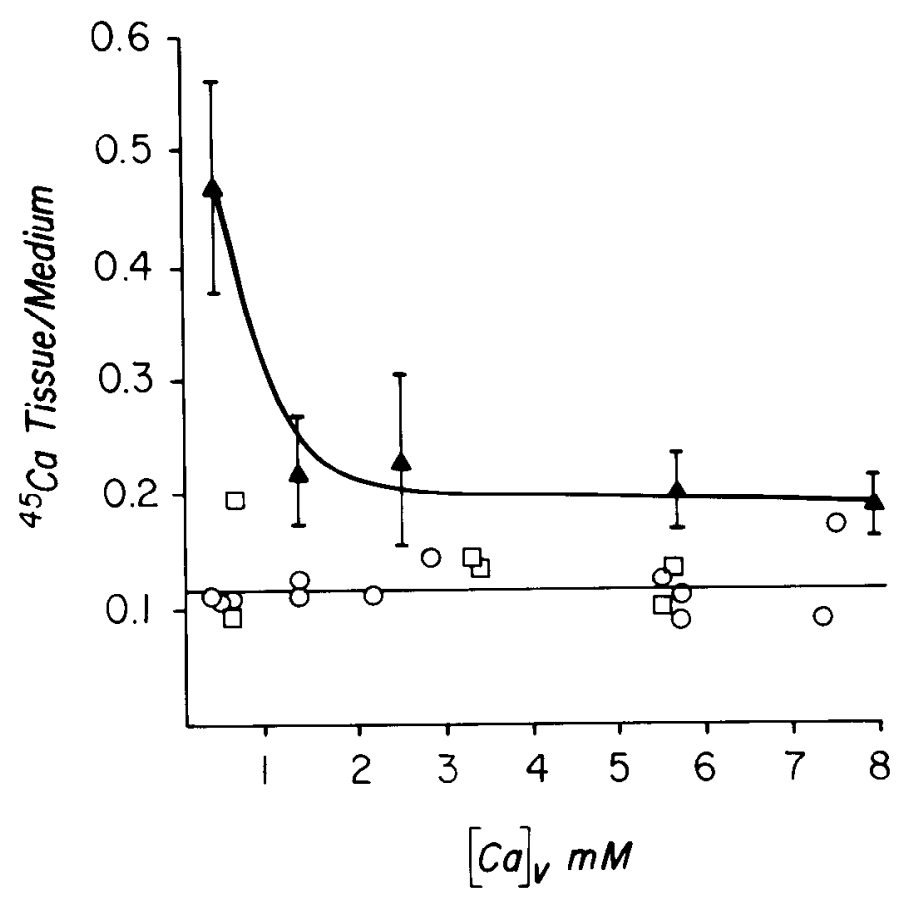

Figure 6. The distribution of ${ }^{45} \mathrm{Ca}$ between tissue and cerebroventricular fluid as a function of the Ca concentration in the cerebroventricular fluid. $\bigcirc$, Brain tissue; $\square$, brain tissue in the presence of $0.1 \mathrm{~mm}$ ruthenium red; $\Delta$, choroid plexus. The vertical bars represent 2 SD. The lines for both choroid plexus and brain were drawn freehand. The concentration of ${ }^{45} \mathrm{Ca}$ in the tissue $(1 \mathrm{gm}=1 \mathrm{ml})$ was determined after $120 \mathrm{~min}$ of ventriculocisternal perfusion. The tissue/medium ratio for the choroid plexus at $C_{v}=0.03$ mm was significantly different ( $p$ $<0.01$ ) from that at higher $C_{v}$ concentrations. it was possible to calculate the amount of ${ }^{45} \mathrm{Ca}$ recovered from the brain at the end of the perfusion period as a fraction of the total endogenous removal of the isotope. The total endogenous removal was obtained as the sum

$$
\int_{0}^{t}\left(V_{\text {in }}{ }^{*} C_{\text {in }}-V_{\text {out }}{ }^{*} C_{\text {out }}\right)
$$

in the experimental samples over the entire period of the perfusion. The mean value for brain uptake of ${ }^{45} \mathrm{Ca}$ in 16 rats accounted for $44 \%(\mathrm{SD}=11)$ of the total endogenous removal; the remaining $56 \%$ was removed to the blood.

\section{Discussion}

At the steady state, the rate of appearance of Ca (moles per min) in the cerebroventricular compartment equals its rate of disappearance. Therefore, the values for $R_{a}$, as measured in the present study, represent the net transport of $\mathrm{Ca}$ after an apparent isotopic steady state was reached between ${ }^{45} \mathrm{Ca}$ in the cerebroventricular compartment and adjacent Ca pools in brain tissue. The $R_{a}$ value measured here corresponds to the $\mathrm{Ca}$ influx $\left(J_{p v}+J_{b v}\right)$ as determined by Graziani et al. (1967) in the cat. These authors found a mean $\mathrm{Ca}$ influx of $40.5 \mathrm{nmol} / \mathrm{min}$ in cats perfused without exogenous $\mathrm{Ca}$, whose CSF production rate was $16 \mu \mathrm{l} / \mathrm{min}$. In the present study, we found a mean $R_{a}$ value of $6.2 \mathrm{nmol} / \mathrm{min}$ in rats which were perfused with an extremely low $\mathrm{Ca}$ concentration (0.08 mM). In an earlier study (Simpson and Barkai, 1980), the mean CSF production rate of the rat was found to be 2.3 $\mu \mathrm{l} / \mathrm{min}$. The ratio of the mean $\mathrm{Ca}$ influx values between the cat and the rat was 6.4 , which is very close to the value of 6.9 calculated for the ratio of the mean CSF formation rate between these two species. These similar ratios indicate a possible close relationship between $\mathrm{Ca}$ influx and CSF formation in these species. Graziani et al. (1967) calculated that only $62 \%$ of the $\mathrm{Ca}$ appearing in the CSF originated in the blood, whereas in the present study, we have found that the entry from blood could account for about $75 \%$ of the $\mathrm{Ca}$ appearing in the cerebroventricular compartment. In an earlier study, Graziani et al. (1965) found that $85 \%$ of the $\mathrm{Ca}$ appearing in the CSF originated in the blood, but they have indicated that their more recent value of $62 \%$ was probably the correct one because, in the earlier experiments, the relative $S A$ values were not corrected for perfusion time. However, the influx coefficient measured by Graziani et al. (1967) and corrected for 60 min represents, in part, an exchange component between the CSF and brain. In their earlier experiments, this coefficient was obtained after prolonged perfusion when isotopic steady state has been reached, and therefore, the contribution of the exchange component was minimal, thus resulting in a higher portion of $\mathrm{CSF} \mathrm{Ca}$ entering from blood. In the present study, the rate of Ca entry from blood measured soon after the isotope injection represents the unidirectional influx which does not include an exchange component with brain tissue. The existence of such an exchange between the cerebroventricular fluid and brain is apparent from the presence of ${ }^{45} \mathrm{Ca}$ in the brain tissue at the end of the perfusion cxperiment. Since the steady state uptake of ${ }^{45} \mathrm{Ca}$ by the rat brain accounted for $44 \%$ 
of the endogenous removal, it would appear that at least $44 \%$ of the Ca which enters the cerebroventricular compartment from blood is exchangeable with brain tissue in this species. The value for $R_{a}$ has been measured here at an apparent isotopic steady state (Fig. 1), and therefore, it does not include the exchange component with brain tissue. Thus, the value for $R_{a}$ should largely represent the net influx of $\mathrm{Ca}$ into the cerebroventricular compartment under steady state conditions.

The removal of $\mathrm{Ca}$ from the CSF compartment was found to be directly proportional to its concentration in the perfusate, with the fractional removal being independent of the mean ventricular concentration (Fig. 4). This result is consistent with the lack of special transport processes for the removal of Ca from the CSF as observed in the dog (Oppelt et al., 1963) or in the cat (Graziani et al., 1965). In the rat, as in the other two species, $\mathrm{Ca}$ is removed from the CSF compartment mainly by diffusion and bulk absorption of the CSF. The removal by diffusion to brain tissue accounted for $44 \%$ of the total endogenous removal compared with about $35 \%$ of the total efflux entering the brain in cats (Graziani et al., 1965). Diffusion to the brain accounted for $67 \%$ of the endogenous removal of $\mathrm{K}^{+}$and for about $12 \%$ of the removal of $\mathrm{Na}^{+}$from the CSF (Cserr, 1965).

The question of the relationship between Ca entry into the $\mathrm{CSF}$ and the concentration of $\mathrm{Ca}$ in the cerebroventricular fluid is addressed for the first time in the present study. The results show that the rate of Ca entry into the CSF is related negatively to the Ca concentration in the ventricular fluid (Fig. 2). This negative relationship suggests that the entry of Ca to the CSF is regulated by a feedback mechanism which is sensitive to changes in the $\mathrm{Ca}$ concentration in the cerebroventricular fluid. It appears from the present results that an increase in the Ca concentration in the CSF may enhance the activity of a Ca pump which acts as a partial barrier for $\mathrm{Ca}$ transport from the blood to the CSF. Such a pump is likely to be located at the sites of Ca entry from the blood to the CSF, presumably at the serosal side of the epithelial cells of the choroid plexus or at the capillary wall. This pump would act to carry $\mathrm{Ca}$ to the blood against the concentration gradient which normally exists between the blood and the CSF. The finding that the addition of ruthenium red was associated with significantly higher $R_{a}$ values which were no longer related to the Ca concentration in the perfusate also supports the notion that a Ca pump is operative in the regulation of Ca entry into the CSF.

Thus, the present results are consistent with the presence of a process of Ca extrusion which may occur at the sites of CSF formation. It is possible that, normally, $\mathrm{Ca}$ diffuses passively across the choroid plexus along narrow tortuous channels in the tight junction which serves as the passive permeation pathway for hydrophilic solutes in this epithelium (Castel et al., 1974). When the Ca concentration in the plasma is elevated (hypercalcemia), as in the experiments of Graziani et al. (1967) for example, the Ca concentration in such tight junction channels is expected to increase, and in turn, the activity of the $\mathrm{Ca}$ pump would be enhanced to increase Ca extrusion. The expected increase in the unidirectional flow of $\mathrm{Ca}$ from the blood to the CSF due to the larger concentration gradient now would be reduced by the process of enhanced $\mathrm{Ca}$ extrusion. These events are directed to maintain the $\mathrm{Ca}$ concentration in the CSF within a limited range. On the other hand, when Ca concentrations in the CSF are manipulated, as in the present experiments, an increased Ca concentration in the CSF might be expected to elevate the $\mathrm{Ca}$ level within the extracellular channels of the tight junctions similarly and, consequently, to enhance the activity of the Ca pump. However, under such circumstances, the unidirectional inflow from the blood is expected to decrease because the concentration of $\mathrm{Ca}$ in the plasma was not changed. The reduction in $R_{a}$ values seen in the present study after the $\mathrm{Ca}$ concentrations in the perfusate were elevated may be explained by such enhancement of a Ca pump activity.

A model for the system which regulates the concentration of $\mathrm{Ca}$ in the CSF is proposed in Figure 7. In this model, $\mathrm{Ca}$ enters the CSF from the blood through the choroid plexus and leaves the cerebroventricular compartment by bulk absorption and transependymal diffusion. The model consists of four compartments: blood, brain, cerebroventricular fluid $(\mathrm{v})$, and choroid plexus (cp), but the present discussion will focus on the last two. A Ca pump is located in the boundary between the $\mathrm{cp}$ and the blood for pumping $\mathrm{Ca}$ unidirectionally to the blood. Simple equations which describe the relationship between the model parameters in $\mathrm{cp}$ and $\mathrm{v}$ are presented in the appendix. According to this model, the relationship between $R_{a}$ and $C_{v}$ (equation $2 \mathrm{a}$ ) is essentially linear with a slope $K_{v \rightarrow c p} \cdot V_{v}$ and an intercept $C_{c p} \cdot K_{v \rightarrow c p} \cdot V_{v} \cdot{ }^{*} C_{v} /$ ${ }^{*} C_{c p}$. When this relationship was plotted using the exper-

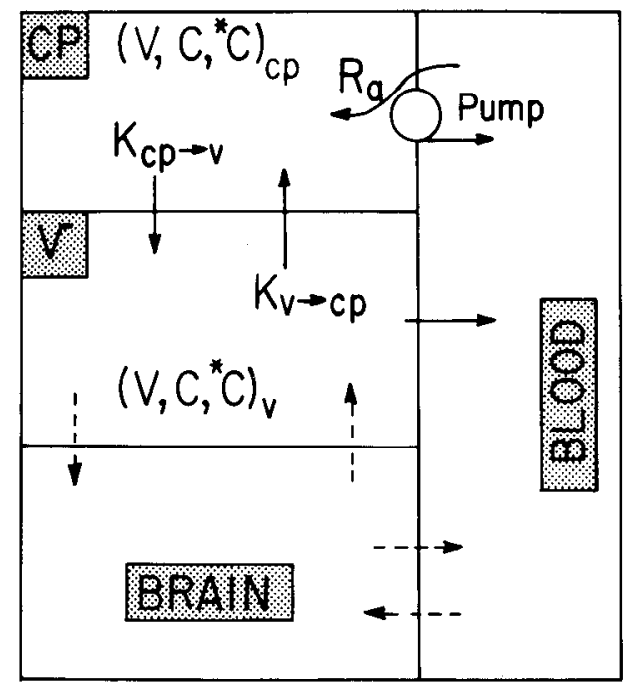

Figure 7. A model for the system which regulates the concentration of calcium in the CSF. The model consists of four compartments: blood, brain, choroid plexus (cp), and cerebroventricular fluid (v). $C_{i}$, Concentration of $\mathrm{Ca}$ in compartment $\mathrm{i}$ (millimolar): ${ }^{*} C_{i}$, concentration of ${ }^{45} \mathrm{Ca}$ in compartment i (counts per min per $\mathrm{ml}$ ); $V_{i}$, volume of compartment $\mathrm{i}$ (milliliters); $K_{i \rightarrow j}$, fractional rate constant for $\mathrm{Ca}$ transfer from $i$ to $j$ (per min); $R_{a}$, rate of appearance of $\mathrm{Ca}$ in $\mathrm{v}$ from blood via $\mathrm{cp}$ (nanomoles per min); Pump, Ca pump located between the blood and cp for pumping Ca unidirectionally to blood. Equations describing the behavior of model parameters are presented in the appendix. 
imental values for $R_{a}$ at the $C_{v}$ range between 1.3 and 8 $\mathrm{mM}$, a slope of $0.52 \mu \mathrm{l} / \mathrm{min}$ was found (Fig. 2). Using a value of $200 \mu \mathrm{l}$ for $V_{v}$ in the rat (Simpson and Barkai, 1980 ), a value of $0.0026 / \mathrm{min}$ was obtained for $K_{v \rightarrow c p}$. When the ratio ${ }^{*} C_{v} /{ }^{*} C_{c p}$ also is known, as in the present experiments, it is possible to calculate the value of $C_{c p}$. The ratio ${ }^{*} C_{v} /{ }^{*} C_{c p}$ was found from the data presented in Figure 6. This ratio equals 5.1 over the $C_{v}$ range between 1.3 and $8 \mathrm{~mm}$. After substitution of the slope $(0.52)$ and the ${ }^{*} C_{v} /{ }^{*} C_{c p}$ ratio in equation $2 \mathrm{a}$ when $C_{v}$ is $1.3 \mathrm{~mm}$ and the corresponding $R_{a}$ is $4.2 \mathrm{nmol} / \mathrm{min}$ (Fig. 2), a value of $1.86 \mathrm{~mm}$ was obtained for $C_{c p}$. Because the cp compartment is not homogeneous and includes intracellular as well as extracellular components, including blood, the calculated $C_{c p}$ values probably reflect a higher concentration of $\mathrm{Ca}$ in the extracellular space of the choroid plexus. Nevertheless, the value for $C_{c p}$ remains unchanged even when the $C_{v}$ is elevated to $8 \mathrm{~mm}$. Furthermore, at the lower range of $C_{v}$ between 0.3 and $1.3 \mathrm{~mm}$, the slope representing the relationship between $R_{a}$ and $C_{v}$ was 2.5 $\mu \mathrm{l} / \mathrm{min}$ (Fig. 2). This higher slope is associated with a lower ${ }^{*} C_{v} /{ }^{*} C_{c p}$ ratio of 2.1 (Fig. 6). A $C_{c p}$ value of approximately $1.5 \mathrm{~mm}$ was calculated using the corresponding values for the slope (2.5), the ${ }^{*} C_{v} /{ }^{*} C_{c p}$ ratio (2.1), $R_{a}$ (6.5) and $C_{v}(0.5)$, in equation 2a. Thus, it appears from this model that the system which regulates the entry of $\mathrm{Ca}$ from the blood to the CSF acts to maintain a relatively steady concentration of $\mathrm{Ca}$ within the choroid plexus even when the Ca concentration in the surrounding medium is varied within a wide range.

\section{Appendix}

In the model shown in Figure 7, when the variables $C_{i}$, $V_{i}, K_{i \rightarrow j}$, and $R_{a}$ are under steady state conditions and when ${ }^{*} C$ is constantly infused into $\mathrm{v}$ until apparent isotopic steady state has been reached between $\mathrm{v}$ and $\mathrm{cp}$ (but not necessarily between $v$ and blood or brain), the following equations can be developed:

$$
C_{v} K_{v \rightarrow c p}+R_{a} / V_{v}=C_{c p} K_{c p \rightarrow v}
$$

solving for $R_{a}$

$$
R_{a}=C_{c p} K_{c p \rightarrow v} V_{v}-C_{v} K_{v \rightarrow c p} V_{v}
$$

also

$$
{ }^{*} C_{v} K_{v \rightarrow c p}={ }^{*} C_{c p} K_{c p \rightarrow v}
$$

or

$$
K_{c p \rightarrow v}=\left({ }^{*} C_{v} /{ }^{*} C_{c p}\right) \cdot K_{v \rightarrow c p}
$$

substituting $K_{c p \rightarrow v}$ in equation 1a above

$$
R_{a}=C_{c p}\left({ }^{*} C_{v} /{ }^{*} C_{c p}\right) \cdot K_{v \rightarrow c p} V_{v}-C_{v} \cdot K_{v \rightarrow c p} \cdot V_{v}
$$

These equations were derived with the assumption that, when apparent isotopic steady state is reached between $\mathrm{v}$ and $\mathrm{cp}$, the amount of ${ }^{*} C$ lost to the blood compartment is diluted in the much larger volume of this compartment and the return of ${ }^{*} C$ from the blood to $\mathrm{v}$ therefore would be negligible.

\section{References}

Barkai, A. I. (1981) Myo-inositol turnover in the intact rat brain: Increased production after $d$-amphetamine. J. Neurochem. 36: 1485-1491.

Castel, M., A. Sahar, and D. Erlij (1974) The movement of lanthanum across diffusion barriers in the choroid plexus of the cat. Brain Res. 67: 178-184.

Cserr, H. (1965) Potassium exchange between cerebrospinal fluid, plasma and brain. Am. J. Physiol. 209: 1219-1226.

Cserr, H. (1971) Physiology of the choroid plexus. Physiol. Rev. 51: 273-311.

Graziani, L., A. Escriva, and R. Katzman (1965) Exchange of calcium between blood, brain and cerebrospinal fluid. Am. J. Physiol. 208: 1058-1064.

Graziani, L. J., R. K. Kaplan, A. Escriva, and R. Katzman (1967) Calcium flux into CSF during ventricular and ventriculocisternal perfusion. Am. J. Physiol. 213: 629-636.

Katzman, R., L. Graziani, and S. Ginsberg (1968) Cation exchange in blood, brain and CSF. In Brain Barrier Systems, A. Lajhta and D. H. Ford, eds., pp. 283-296, Elsevier, New York.

Lowry, O. H., N. J. Rosebrough, A. L. Farr, and R. J. Randall (1951) Protein measurement with the Folin phenol reagent. J. Biol. Chem. 193: 265-275.

Oppelt, W. W., E. D. Owens, and D. P. Rall (1963) Calcium exchange between blood and cerebrospinal fluid. Life Sci. 2: 599-605.

Riggs, D. S. (1963) The Mathematical Approach to Physiological Problems, pp. 200-201, William \& Wilkins, Baltimore.

Simpson, L. L., and A. I. Barkai (1980) Kinetic studies on the entry of $d$-amphetamine into central nervous system. I. Cerebrospinal fluid. J. Pharmacol. Exp. Ther. 212: 541-545.

Watson, E. L., F. F. Vinconzi, and P. W. Davies (1971) $\mathrm{Ca}^{+2}-$ activated membrane ATP-ase: Selective inhibition by ruthenium red. Biochim. Biophys. Acta 249: 606-610.

Wright, E. M. (1972) Mechanisms of ion transport across the choroid plexus. J. Physiol. (Lond.) 226: 545-571. 